\title{
BMJ Global Health How previous epidemics enable timelier COVID-19 responses: an empirical study using organisational memory theory
}

\author{
Sian Hsiang-Te Tsuei ${ }^{1,2}$
}

To cite: Tsuei SH-T. How previous epidemics enable timelier COVID-19 responses: an empirical study using organisational memory theory. BMJ Global Health 2020;5:e003228. doi:10.1136/ bmjgh-2020-003228

Handling editor Seye Abimbola

Received 25 June 2020 Revised 21 August 2020 Accepted 22 August 2020
Check for updates

(c) Author(s) (or their employer(s)) 2020. Re-use permitted under CC BY-NC. No commercial re-use. See rights and permissions. Published by BMJ.

${ }^{1}$ Global Health and Populations, Harvard University T H Chan School of Public Health, Boston, Massachusetts, USA

${ }^{2}$ Centre for Health Education Scholarship, University of British Columbia, Vancouver, BC, Canada

Correspondence to Sian Hsiang-Te Tsuei; stsuei@g.harvard.edu

\section{ABSTRACT}

Introduction There has been little systematic exploration into what affects timeliness of epidemic response, despite the potential for earlier responses to be more effective. Speculations have circulated that previous exposure to major epidemics helped health systems respond more quickly to COVID-19. This study leverages organisational memory theory to test whether health systems with any, more severe, or more recent exposure to major epidemics enacted timelier COVID-19 policy responses.

Methods A data set was constructed cataloguing 846 policies across 178 health systems in total, 37 of which had major epidemics within the last 20 years. Hypothesis testing used OLS regressions with World Health Organization region fixed effects, controlling for several health system expenditure and political variables.

Results Results show that exposure to any major epidemics was associated with providing earlier response in the following policy categories: all policies, surveillance/ response, distancing, and international travel policies. The effect was about $6-10$ days earlier response. The significance of this variable was largely nullified with the addition of the other two independent variables. Neither total cases nor years since previous epidemics showed no statistical significance.

Conclusion This study suggests that health systems may learn from past major epidemics. Policymakers ought to institutionalise lessons from COVID-19. Future studies can examine specific generalisable lessons and whether timelier responses correlated with lower health and economic impacts.

\section{INTRODUCTION \\ Background}

The drastic consequences of COVID-19 highlight the need to identify tactics that could have mitigated these outcomes. Earlier interventions are particularly worthwhile, as such policies might use simpler techniques such as border control or isolated case finding followed by quarantine. In contrast, once a disease has established a foothold, interventions may require expensive life-supporting therapies or aggressive public health measures

\section{Key questions}

What is already known?

- There has been little systematic exploration into what affects the timeliness of response to epidemics.

- For COVID-19, there has been speculation that previous exposure to major epidemics may have spurred timelier responses.

What are the new findings?

- Applying organisational memory theory, this study identified some support for the hypothesis that policy response timeliness to COVID-19 may be associated with any past exposure to major epidemics within the last 20 years.

What do the new findings imply?

- The fact that any exposure to past epidemics is associated with timelier responses suggest that health systems may learn from past experiences.

- Institutionalising the learnings through more permanent policies may therefore be necessary.

- Once COVID-19 fades, health systems may wish to revitalise the organisational memory through various exercises.

that might cause significant socioeconomic disruptions. Later interventions may be also less effective. Asymptomatic transmission for diseases like COVID-19 may elude effective containment strategies unless implemented universally. Therefore, it is particularly important to examine how the pandemic could have been limited to earlier stages.

There has been report of improving timeliness of disease outbreak recognition. ${ }^{1}$ However, there is little rigorous exploration on what drives timeliness of policy response to epidemics. Kandel et al examined in 2020 the capacity for 182 countries to respond to public health emergencies. ${ }^{2}$ They constructed operational readiness index based on select metrics from the domains of (a) technical abilities, including the ability to conduct 
surveillance, contact tracing and infection prevention; (b) governance capacity, marked by capacity for multisectoral collaboration, emergency risk communication and (c) resource availability, defined in terms of finances and human resources. However, these indices were constructed neither systematically nor empirically.

Other attempts to explore epidemic response timeliness have typically drawn on sporadic posthoc reviews or case studies. For example, the US Center for Disease Control (CDC) documented that it responded quickly within the month that the Middle East Respiratory Syndrome Coronavirus (MERS-CoV) case was reported to the online Programme for Monitoring Emerging Diseases. It mobilised its personnel to begin collecting more information, quickly developed briefings for staff members and the general public, and posting travel updates. ${ }^{3}$

The literature has typically shied away from rigorous frameworks to examine how timely response to epidemics could be enacted. One study, however, did attempt such a methodology. Hanvoravongchai et al examined the six Asian health systems' preparedness for an influenza pandemic. They concluded that more prepared health systems had pandemic response integrated into national disaster preparedness framework, lower public health official turnovers, previous pandemic exposures and more political emphasis on preparedness. Nevertheless, their work was focused on generating hypotheses rather than testing hypotheses, and as such, there is a dearth of literature that systematically tests a developed hypothesis on what affects timeliness of epidemic response.

\section{Objectives}

This study aims to explore why health systems differ in their timeliness of issuing policy responses to COVID-19 before the epidemic took hold. Exploring what drives timelier response may point future health system researchers and policymakers in fruitful directions.

The WHO has defined health system explicitly to capture 'all the activities whose primary purpose is to promote, restore or maintain health'. Among the various actors within health system, this study specifically focuses on the executive branch of the government. Their attempt to minimise COVID-19 burden through prevention is captured within the definition of health system. The focus on such an organisational consideration in health systems is particularly worthwhile, since it is traditionally more opaque and de-emphasised particularly among low-income and middle-income countries. ${ }^{6}$ This is unfortunate because it is the dynamics and bureaucratic abilities within the guiding government bodies that affect the policy development. Specifically, the dynamics within the executive branch of government determine policy responses, and this branch is particularly relevant for epidemic responses. First, they can respond most swiftly in an emergency. The legislative branch often requires passing several readings of the law and the judicial branch is responsible for ex post interpretation of laws. Second, the executive branch drives the responses of subsidiary government organisations, providing targets and support for organisations such as the CDC. Here, the executive branch is considered as a single decision-making unit, experiencing the relevant dynamics together, since the relevant parties within this unit must reach a consensus on the relevant policies.

\section{Hypothesis 1}

The popular media claims that the countries with more serious exposures to SARS or MERS-CoV responded more appropriately to COVID-19. ${ }^{78}$ The intuition is that the health systems faced with infections with potentially high risk of case fatality rate in the past have learnt from their past experiences, and can therefore cope better, be it more promptly or more effectively. In this case, the diseases identified have been found to have case fatality rate of greater than $1 \%$.

Such intuitive reasoning resonates with both organisational memory theory and institutional memory theory. Organisational memory is defined as the "stored information from an organization's history that can be brought to bear on present decisions, ${ }^{, 9}$ and institutional memory is defined similarly as organisational elites' 'shared knowledge...about past crisis management.. ${ }^{10}$ Given the richer development of the organisational memory theory, however, I favour the organisational memory term for the rest of the paper. In Walsh and Ungson's seminal review of organisational memory, they describe that relevant information about a problem and associated decision is encoded within an organisation via several methods, such as individuals' memories, organisational procedures and organisational cultures. ${ }^{9}$ When a similar problem surfaces again, the organisation retrieves the stored information. Assuming that the executive branch personnel aim for timelier responses, this therefore leads to the first hypothesis:

Having at least one case of a disease that is highly threatening within the last 20 years is associated with more timely response.

\section{Hypothesis 2}

The duration of the lessons may be non-permanent depending on the way the lessons were encoded. If encoded into policies, the lessons may last as long as the institution itself. However, Walsh and Ungson suggest that much of the organisational memory is encoded within the individuals' memories, ${ }^{9}$ rendering the lessons impermanent. As more individuals exposed to the problem retire, the relevant lessons and expertise fades. With more recent exposures, the memory of the relevant procedures allows more appropriate response. This therefore generates the second hypothesis:

The more time elapsed since the last major epidemic in a health system, the slower the response in the health system.

\section{Hypothesis 3}

Psychology has shown also that the depth of memory correlates with the intensity of the emotions during the event. ${ }^{11} 12$ The stronger the emotion, the stronger the activation of 
Table 1 List of data sets with their respective content and sources

\begin{tabular}{lll}
\hline Data set name & Content & Source(s) \\
\hline Past epidemics exposure & $\begin{array}{l}\text { Number of cases, deaths and years affected by SARS, H1N1, MERS, Ebola } \\
\text { Note: Saudi Arabia's MERS burdens were hand coded based on review of } \\
\text { the monthly reports of Disease outbreak News. }{ }^{21} \text { Data available on request. } \\
\text { Seychelles' international travel ban was modified to 3 February 2020. }\end{array}$ & 20 21 23-26 \\
\hline COVID-19 cases and deaths & Day-by-day number of cases and deaths of COVID-19 & 27 \\
\hline $\begin{array}{l}\text { Public health and social } \\
\text { measures }\end{array}$ & $\begin{array}{l}\text { Number, type and content of policy measures for COVID-19 as classified by WHO } \\
\text { and up-to-date as of 14 May 2020 }\end{array}$ \\
\hline $\begin{array}{l}\text { Corruption Perception Index } \\
\text { GDP per capita }\end{array}$ & $\begin{array}{l}\text { Population's perception of corruption } \\
\text { GDP per capita in current US dollars in 2018 }\end{array}$ \\
\hline Health priority & Note: Taiwan's GDP per capita was supplemented. ${ }^{30}$ & 39 \\
\hline Population size & Health expenditure as a percentage of all GDP in 2018 \\
\hline
\end{tabular}

emotional processing centre amygdala, leading to more lasting encoding of the memories in the hippocampus. ${ }^{13}$ The more severe the previous epidemic, the more likely that the involved individuals would retain the lessons for prolonged period. It follows then that the more serious the last epidemic the executive branch faced, the deeper the episodic memory. This leads to the following hypothesis:

The more cases a health system dealt with in past major epidemics, the timelier the policy responses in the health system.

\section{METHODS}

\section{Study design}

This study uses a cross-sectional regression to assess the association between exposure to major epidemics previously and timeliness of COVID-19 response.
Major epidemics were included if they: occurred within the last 20 years (ie, years 2000-2020), were documented within the WHO Disease Outbreak Network, had case fatality rate $>1 \%$, affected multiple health systems and affected more than 500 cases in total. Diseases were excluded if they had vaccines available at the time of the outbreak, were vector-borne diseases or were COVID-19. This process resulted in the following diseases: SARS, H1N1, Ebola and MERS. However, given that estimates for H1N1's case fatality rate is generally lower and more variable, separate analyses were conducted without H1N1. ${ }^{14}$ Health systems were considered to have been affected by these diseases if they had any cases of the disease during the outbreak (ie, not relying on retrospective modelling parameters). All countries listed in World

Table 2 List of variables and their respective operational definitions

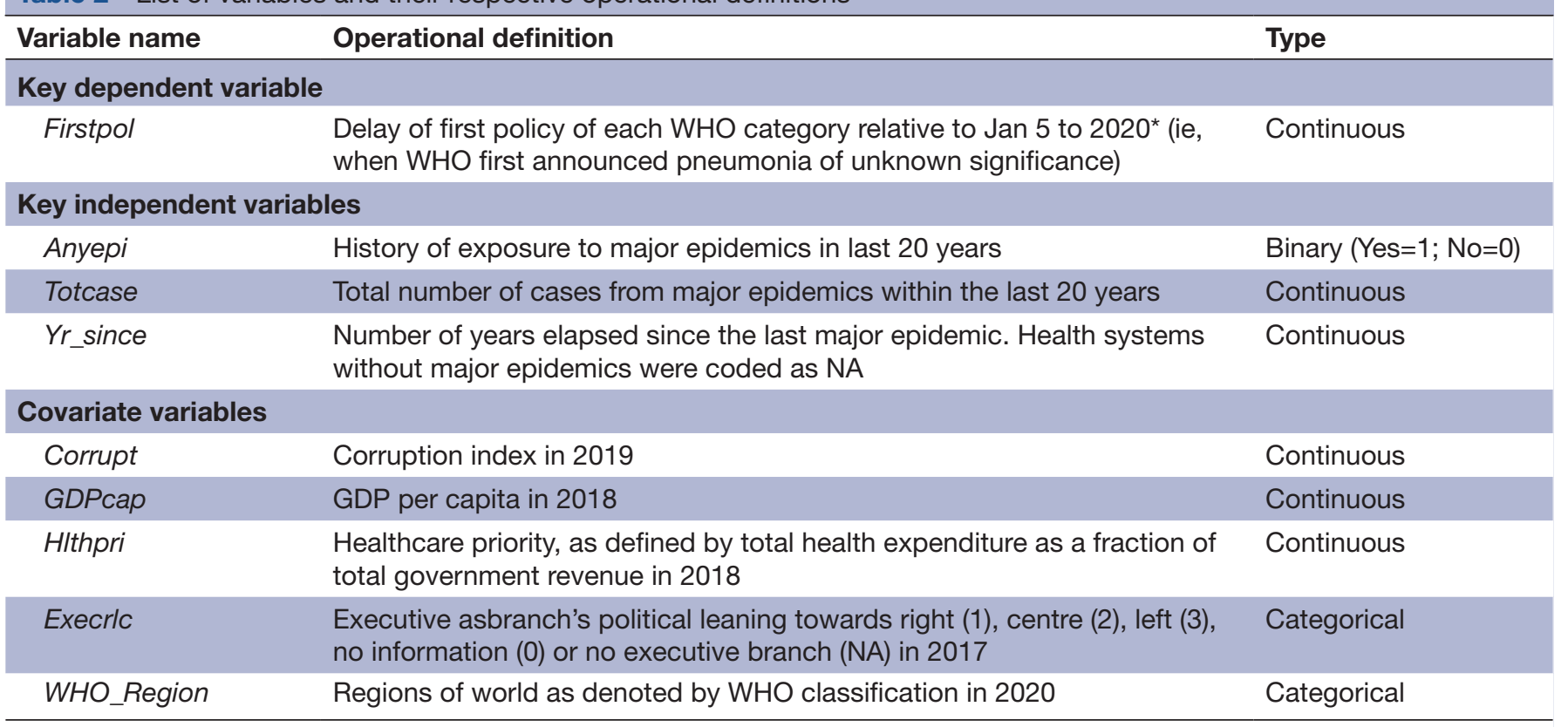

*For completeness, the variable was also defined relative to 31 December 2019, which was when China reported pneumonia of unknown significance to the WHO. 
Table 3 Descriptive statistics for dependent and independent variables stratified by inclusion of $\mathrm{H} 1 \mathrm{~N} 1$ and covariates stratified by exposure to previous epidemics

\begin{tabular}{|c|c|c|c|c|c|c|}
\hline Variables & $\begin{array}{l}\text { Mean or } \\
\text { number }\end{array}$ & $\begin{array}{l}\text { SEM or } \\
\text { proportion }\end{array}$ & $\mathbf{N}$ & $\begin{array}{l}\text { Mean or } \\
\text { number }\end{array}$ & $\begin{array}{l}\text { SEM or } \\
\text { proportion }\end{array}$ & $\mathbf{N}$ \\
\hline Including H1N1 & & & & \multicolumn{3}{|c|}{ Excluding H1N1 } \\
\hline \multicolumn{7}{|l|}{ Dependent variable } \\
\hline First policy delay since 5 January to 2020 & 53.63 & 0.99 & 846 & 53.63 & 0.99 & 846 \\
\hline \multicolumn{7}{|l|}{ Independent variables } \\
\hline Any epidemics in last 20 years & 246 & 0.25 & 846 & 186 & 0.22 & 846 \\
\hline Total cases due to epidemics in last 20 years & 243.26 & 50.24 & 846 & 241.83 & 50.24 & 846 \\
\hline Number of years since last epidemics & 8.92 & 0.34 & 289 & 9.24 & 0.38 & 270 \\
\hline \multicolumn{7}{|l|}{ Covariates } \\
\hline With epidemics exposure & & & & \multicolumn{3}{|c|}{ Without epidemics exposure } \\
\hline Corrupt & 54.83 & 1.37 & 208 & 41.49 & 0.71 & 638 \\
\hline GDP per capita & 27197 & 1539 & 203 & 12649 & 784 & 617 \\
\hline Total health expenditure per capita & 7.21 & 0.23 & 202 & 6.34 & 0.09 & 605 \\
\hline Executive branching leaning & & & 202 & & & 557 \\
\hline Right & 58 & 0.29 & & 97 & 0.17 & \\
\hline Centre & 15 & 0.07 & & 54 & 0.1 & \\
\hline Left & 52 & 0.26 & & 130 & 0.23 & \\
\hline No information & 77 & 0.38 & & 276 & 0.5 & \\
\hline WHO Region* & & & 208 & & & 638 \\
\hline AFRO & 26 & 0.13 & & 170 & 0.26 & \\
\hline AMRO & 16 & 0.08 & & 142 & 0.22 & \\
\hline EMRO & 43 & 0.21 & & 58 & 0.09 & \\
\hline EURO & 49 & 0.24 & & 207 & 0.32 & \\
\hline SEARO & 15 & 0.07 & & 32 & 0.05 & \\
\hline WPRO & 59 & 0.28 & & 29 & 0.05 & \\
\hline
\end{tabular}

${ }^{*}$ The WHO regions are defined as follows: AFRO, African region; AMRO, Americas; EMRO, Eastern Mediterranean; EURO, European Region; SEARO, South-East Asia Region and WPRO, Western Pacific Region.

$\mathrm{N}$, number of observations.

Bank database were considered. Health systems were parsed out from countries list if they have unique health system operations (this recoding mainly affected Hong Kong and Taiwan). This resulted in a total of 177 health systems.

The number of policies considered were the first policies of each of the first five WHO categories. The data set included a total of 846 policies, made up of 82 individual measures, 91 environmental measures, 177 surveillance and response measures, 177 social and physical distancing measures and 188 international travel measures.

\section{Data set and variables}

The timeliness of response was the difference in days between the policy issuance and 5 January 2020, when WHO first announced the pneumonia of unknown significance. The policies are grouped according to the WHO Codes, separated into individual measures, environmental measures, surveillance and response measures, social and physical distancing measures and international travel measures. One category of policy was coded separately to capture the first of all policies within the health system. Each health system therefore would generate one unique first policy overall, and one first policy per WHO category. For completeness, the timeliness of response was also calculated with regard to 31 December 2019, which was when China first notified its WHO division with regard to pneumonia of unknown significance. This was examined as well, given that some health systems such as Taiwan reacted on that day.

Exposure to any major epidemics accounts for exposure to any of the included diseases. Total number of cases tabulates the total number of cases resulting from the included diseases. Years since epidemics were calculated in terms of the number of years between 2020 and the last year the disease occurred in the health system. The data set also included several variables that may affect executive governments' decision process and confound the relationship between policy timeliness and 
organisational memory. Covariates include corruption, fiscal spending and executive government's political preferences. Geographically specific cultures are proxied using WHO regions. Healthcare spending priority is proxied using total health expenditure as a proportion of total government revenue.

The covariates were chosen based on theory. Relying on a deterministic framework is particularly useful given the complexity of the health system and the potential for numerous interconnected pathways. The choices leaned specifically on the renowned control knob framework, ${ }^{15}$ which describes the factors that determine the various outcomes of interest in a health system. The major control knobs include financing, the amount of money available for health-related activities; payment, the method of reimbursement for health-system labour; organisation, the characteristics of health system organisation; regulation, the various policies available for guiding health system actors; and persuasion, which include promotional activities that affect people's preferences.

The main covariates in this study mainly relates to financing and organisation. Financing capacity is captured by the variables on GDP per capita and the proportion of GDP spent on health. Organisational covariates include political leanings and the extent of corruption. This study does not control for payment, regulation, and persuasion control knobs and the implications are addressed in the Bias section of the study.

Another covariate controlled for the date of the first case in the health system. The timeliness of policy responses likely was affected by the timing of the first case, and if the entry of the first case correlated with any of the three independent variables of interest, this could result in confounding.

The list of data sets and variables are provided in tables 1 and 2, respectively.

\section{Statistical methods}

The estimations relied on variations of equation 1 .

Firstpol $_{i, j}=\alpha+\beta_{i}$ Anyepi $_{i, j}+\beta_{2}$ Totcase $_{i, j}+\beta_{3}$ Yr $_{-}$since $_{i, j}+\gamma_{1} X_{i, j}+$

$$
\gamma_{2} \text { WHO_Region }_{i, j}+\varepsilon_{\mathrm{i}, \mathrm{j}}
$$

Equation 1 tests whether the first policy relative to 5 January 2020 for health system $i$ in WHO region $j$ is associated with exposure to any epidemics $\left(\beta_{1}\right)$, total cases $\left(\beta_{2}\right)$ and years since last major epidemics $\left(\beta_{3}\right)$ while controlling for the vector of health system covariates $X$ (the firstpol variable was also specified relative to 31 December 2019, but this changed only the intercept. This phenomenon is addressed further in the results section. The study therefore focused on presenting analysis using delay of policy relative to 5 January 2020). The firstpol variable indicates the health system's very first policy, as well as the health system's first policy within each WHO category.

The equation varied by testing all permutations of the three independent variables. The permutations included a single variable, combinations of two variables and all three variables together. The equation also used WHO Region fixed effects. Standard errors were not clustered to minimise false rejections of the null hypothesis. The coefficients $\beta_{1}, \beta_{2}$ and $\beta_{3}$ are expected to be negative, which will suggest that any exposure to epidemics or higher total cases from epidemics.

\section{Bias}

Residual confounding may arise in three separate places. First, the lack of control for other control knobs may be the most potent cause of residual confounding. While this was in part due to the lack of available data, I suggest some reasons why the potential bias may be minimal. The payment methods for the executive branch of the government are typically salary-based, given that this is usually how governments pay their employees. The understandably uniform method of payment lowers the potential for bias. Regulation and persuasion with regard to COVID-19 are important for affecting the timeliness of response, but they were understandably missing at the outset of the pandemic. In fact, the timeliness of the policy implementation for regulations and persuasions are the matter of the study. Second, some of the indices were available only for 2017 or 2018. The regression dropped health systems for which there were missing covariates. This differential attrition typically involves underdeveloped countries. Because these countries could have responded either more quickly or more slowly to COVID-19, it is difficult to predict the direction of bias. Third, the study controls for the date of first case in the health system but does not control for when the first case arrived in a neighbouring health system or region. This may also cause residual confounding.

\section{Patient and public involvement}

Patients or the public were not involved in the design, or conduct, or reporting or dissemination plans of the research.

\section{RESULTS \\ Descriptive data}

On average, the delay of the first policy relative to the first WHO announcement of COVID-19 was approximately 54 days. About $25 \%$ of the data set included policies from health systems exposed to any history of epidemics, translating to 41 health systems having been exposed to any major epidemics within the last 20 years. The epidemics affected on average about 243 cases. Among health systems exposed to major epidemics, the average was about 9 years since last epidemic. The values of these variables were largely the same when the data set excluded $\mathrm{H} 1 \mathrm{~N} 1$ as a major epidemic.

The descriptive analysis also examined the distribution of all the policies' covariates. This analysis included the policies for all the health systems and stratified according to previous epidemics exposure. The policies in health systems with previous exposure to epidemics tended to be from governments that were more corrupt (corruption 
A

A All Policies

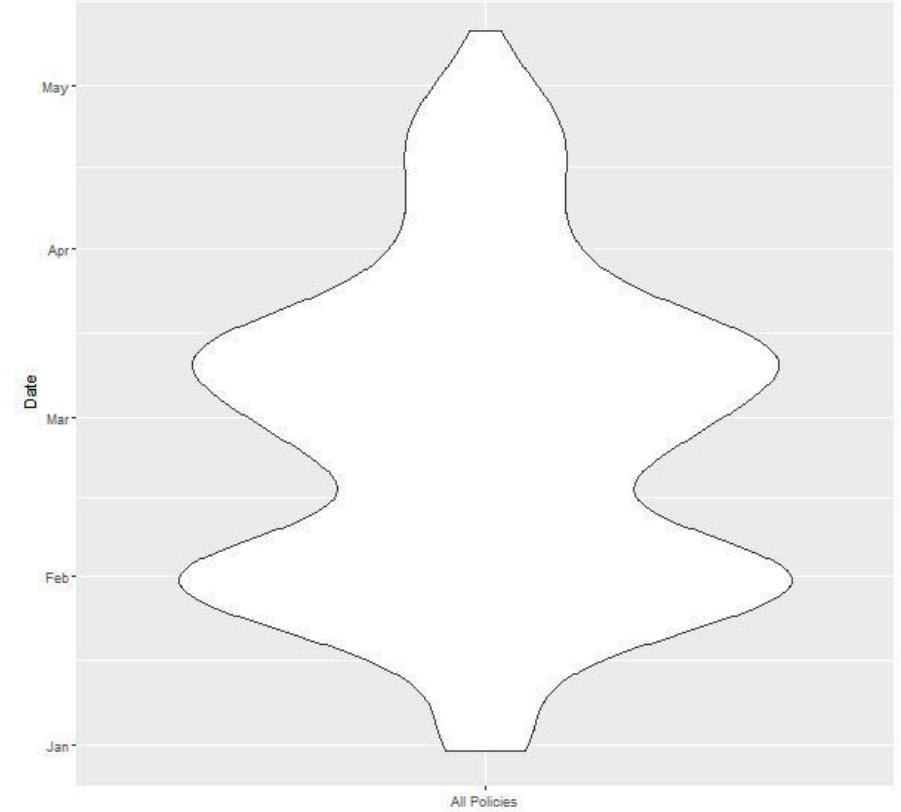

Distribution of Policies Over Time

B By Policy Subtypes

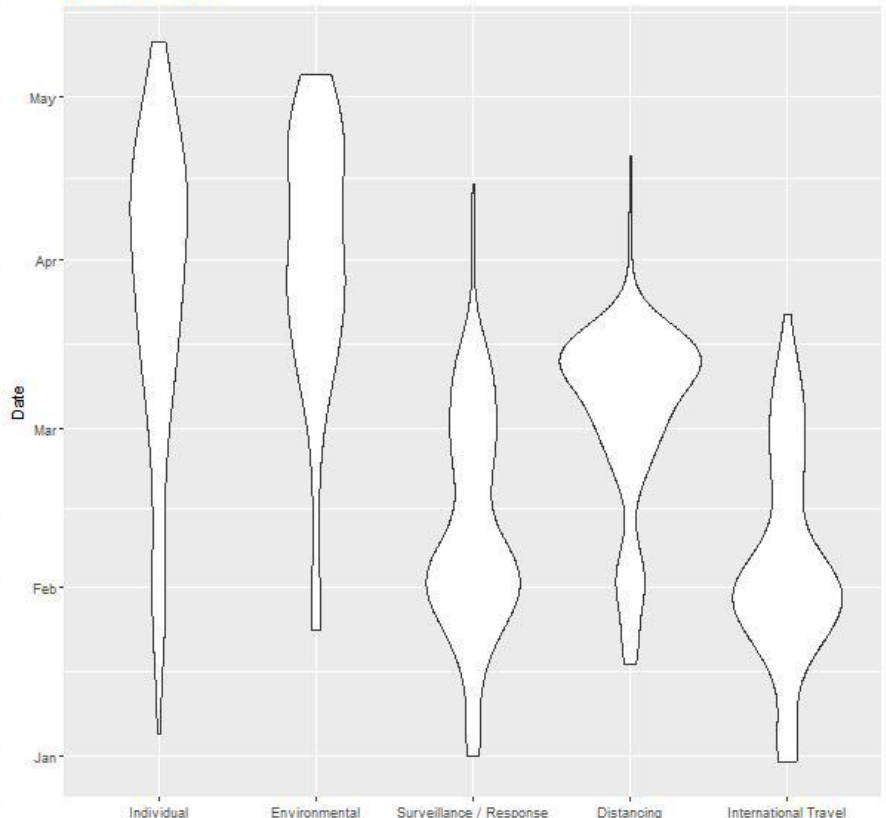

Figure 1 Distribution of policies over time. (A) The distribution of each health system's first policy across all subcategories. (B) The distribution of each health system's first policy, divided by subcategory.

index at 54.83 vs 41.49), enjoyed higher GDP per capita (current USD 27197 vs 12,649), prioritised the healthcare expenditure somewhat (total health expenditure as a proportion of GDP at $7.21 \%$ vs $6.34 \%$ ) and appeared to be more right-winged $(0.29 \%$ vs $0.17 \%$ with right wing executive branch). In terms of the geographical distribution, policies from health systems with previous epidemic exposure also tended to be more concentrated in the African region (13\% vs 26\%), Eastern Mediterranean region $(21 \%$ vs $9 \%)$, and Western Pacific region $(28 \%$ vs $5 \%$ ). Conversely, these health systems were less likely to be in the Americas ( $8 \%$ vs 22\%) and European region (24\% vs 32\%). This leaves the South-East Asian region, which had comparable proportion of policies issued by health systems with and without epidemics exposure $(7 \%$ with exposure vs $5 \%$ without). The descriptive results are summarised in table 3 .

In aggregate, the policies mostly centred around February and mid-March. When broken down by categories, the bulk of the international travel and surveillance/response policies occurred first, occurring around February. The distancing measures then appeared, concentrated mostly around mid-March. Subsequently, the individual and environmental policies occurred, concentrating mostly around April to May. The policy distributions are summarised in figure 1.

The relationship of the three independent variables is also plotted out graphically against the timeliness of any policy response for the data set including H1N1 and specifying delay of response relative to 5 January 2020. The relationship between any exposure to major epidemics and policy response timeliness showed the most striking negative relationship. The total number of cases and years since previous epidemics did not demonstrate much association with timeliness of response. This graphical relationship is demonstrated in figure 2, and is similar to the graphical representation that excluded H1N1 (available on request).

\section{Main results}

Results of analysis including H1N1 suggest that any epidemic exposure is associated with timelier policy responses when examining all policies, or within the categories of surveillance/response, distancing measures and international travel policies by itself. Where significant, the effect of any epidemic exposure was to shorten the policy response by about 6-10 days. Once the total cases are introduced, only the subcategories of policies demonstrated significant association between previous exposure and timeliness. The significance of this variable for any categories of policies is nullified when examined alongside years since previous epidemics.

The epidemics exposure was not significantly associated with timelier individual or environmental policies in any of the specifications. Part of the reason for the lack of significance may be due to the limited df available for the estimations in the individual or environmental policies, as well as for any specifications involving years since epidemics.

The total number of cases and years since the previous epidemics were not significant in any of the specifications. The results of all permutations of the regressions are provided in table 4 .

The results without $\mathrm{H} 1 \mathrm{~N} 1$ are provided in table 5 . It showed somewhat similar results though there are even less occasions of statistical significance. The effect 
Relationship of Key Variables vs. Delay of First Policy

A Effect of Any Epidemic Exposure

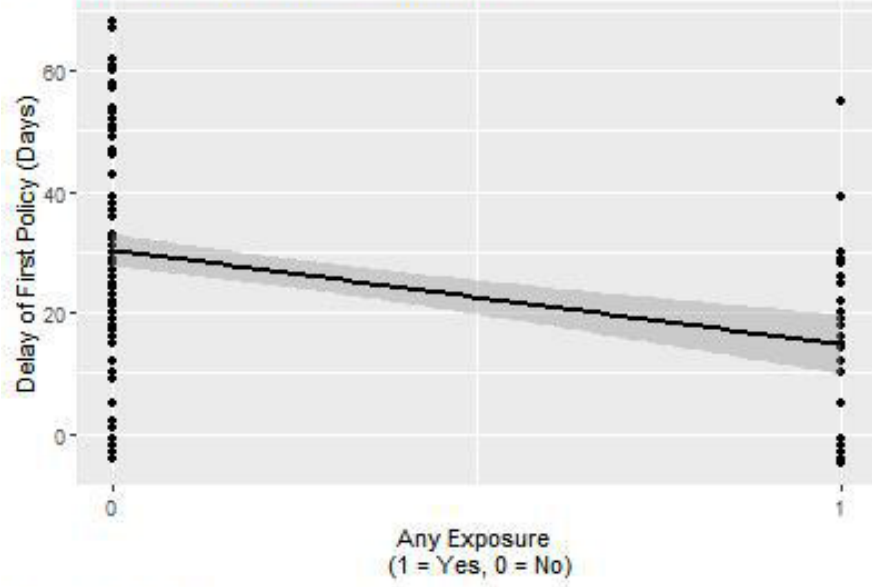

C Effect of Time Since Last Epidemic
B Effect of Case Burden

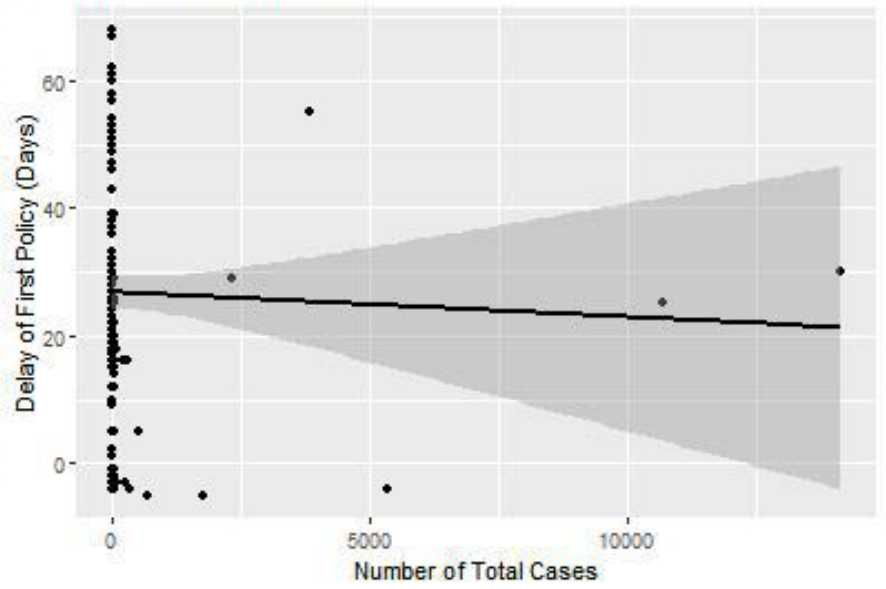

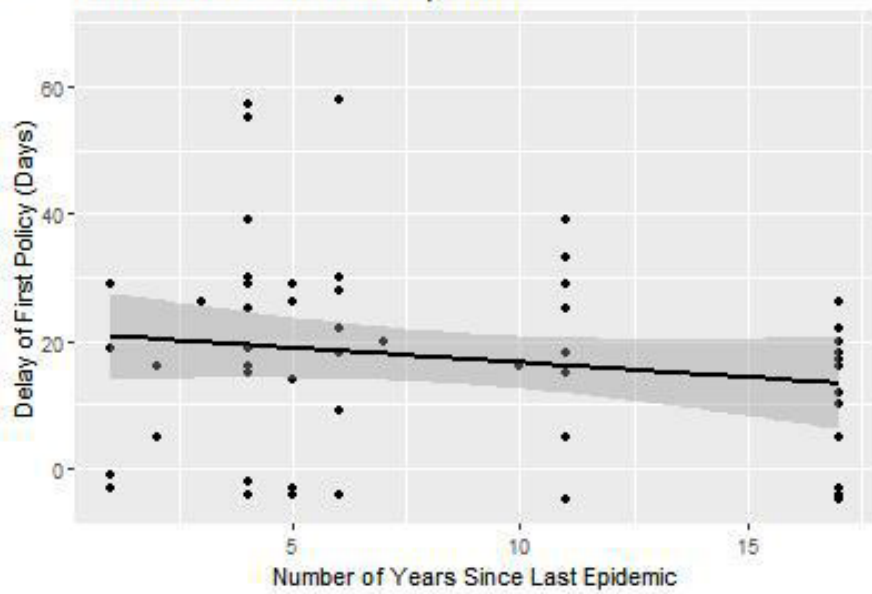

Figure 2 Bivariate relationship between key independent variables and delay of any first policy. A, B and C show, respectively, the relationship between the timeliness of policy response and any exposure to major epidemics in last 20 years, total burden of cases from these major epidemics and time since last major epidemic.

of any epidemics exposure is significant mainly when examined on its own for distancing and international travel measures, and when examined for environmental measures and distancing measures in estimation with total cases. Even when significant, the effects were only borderline significant.

The results that specified policy delays relative to 31 December 2019 shifted the intercepts by five. Since the parameters of interest are the coefficients and they remain unchanged, these additional results are not shown.

\section{DISCUSSION}

\section{Key results and interpretation}

This study is, as far as I know, the first to formally apply organisational memory theory to explore the timeliness of COVID-19 response. This study identified that there may be shorter delays to initial policies when exposed to any previous epidemics within the last 20 years. The association between policy timeliness and organisational memory was significant only relative to any epidemics exposure, but not relative to the number of total cases or the recency of the exposures. The lack of significance for total cases or recency, however, may have been restricted by the sample size.

The policy response timing was quicker by about 6-10 days. Relative to the average delay of policies that was about 54 days, the timeliness improved by about $11 \%-19 \%$ among health systems with previous epidemics exposure. This seemed to be a moderate sized effect, and given the potential for exponential increase of infectious diseases, a respectably faster response. Developing correlations of faster response with burden of disease though would perhaps be useful next steps.

\section{Policy implication}

Since this study showed that exposure to recent epidemics compared no such exposures was associated with faster response, it suggests that health systems may learn from past experiences. Although there is insufficient evidence in this study to suggest that such learnings erode over time, institutionalising the learnings appropriately through more permanent policies may nevertheless be 


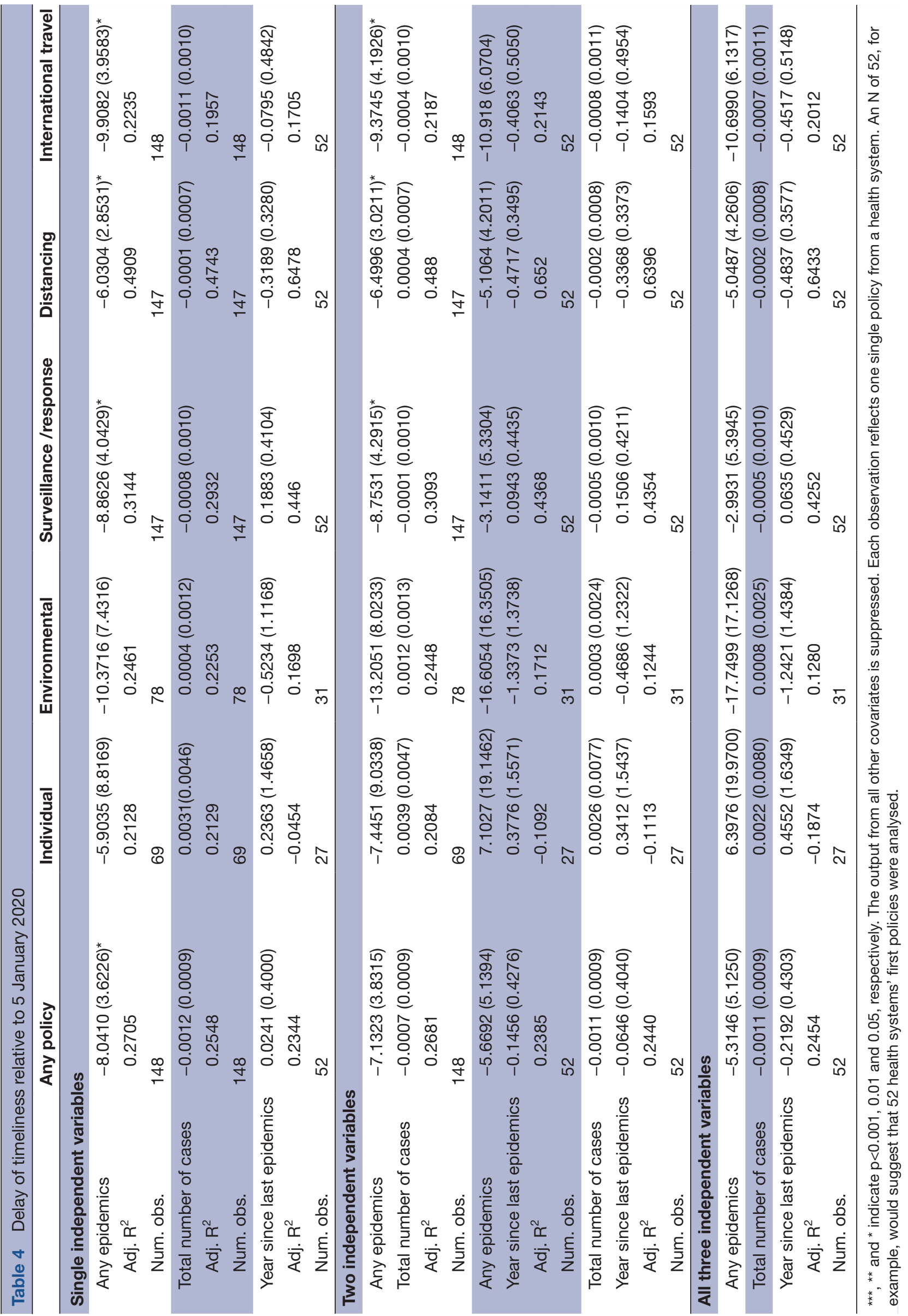




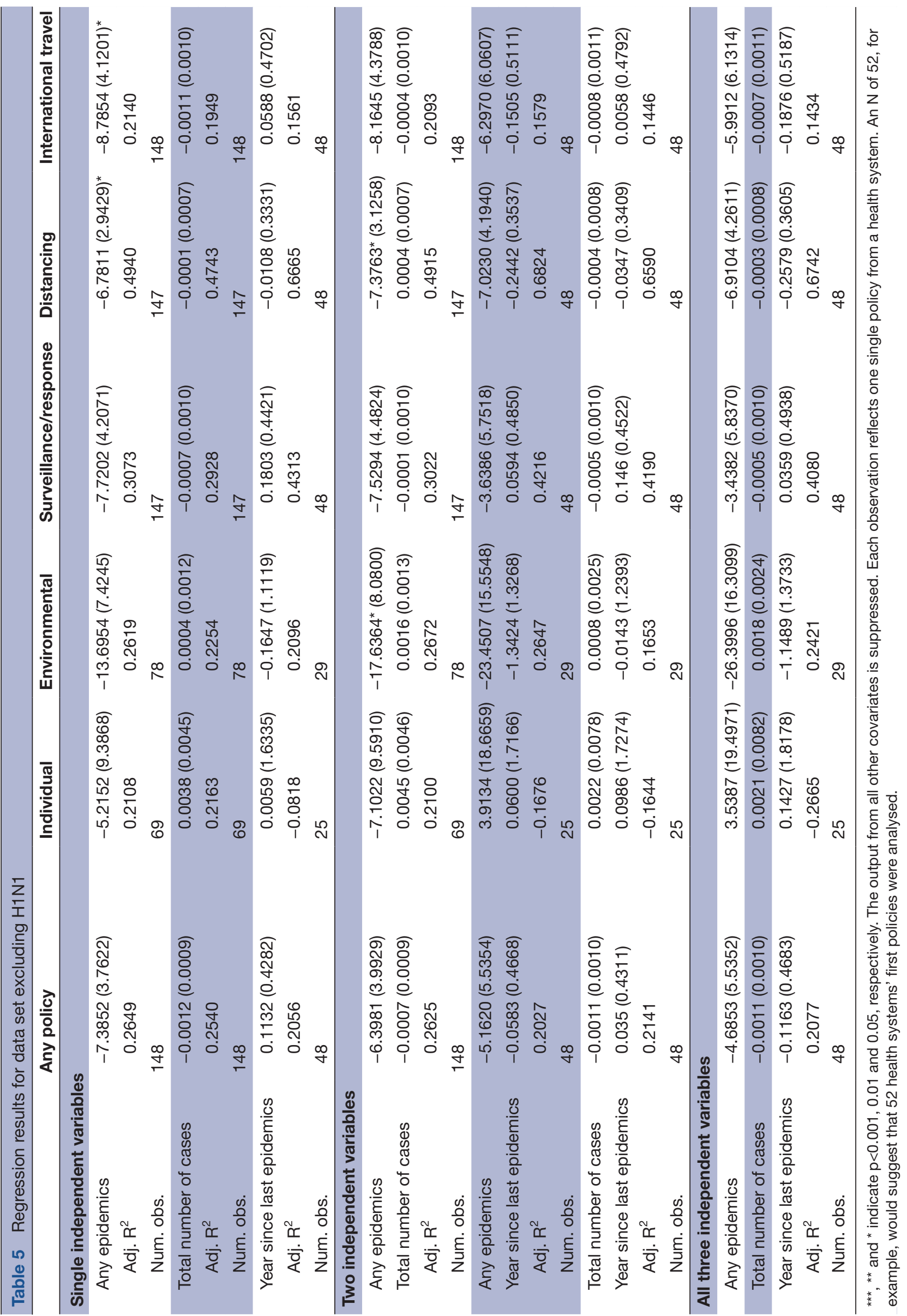


useful. Taiwan, for example, instituted a law soon after SARS epidemic in 2003 to allow the government to establish a Central Epidemics Command Center that can coordinate multisectoral responses efficiently, minimising the barriers of red tapes during epidemics. ${ }^{16}$

It may also be useful for health systems to conduct exercises intermittently to jog the organisational memory. Hanvoravongchai $e t a t^{t}$ have suggested that the epidemic preparedness drills may have either blossomed or minimised depending on local elites' support for such exercises. Therefore, a clear implication may be that such drills need to be legally mandated with clear specification regarding the scope, and frequency.

\section{Future research avenues}

Peeri et $a l^{17}$ suggest that health systems may have learnt to communicate with the public more regarding hygiene and establish quarantine processes, but political leaders had not appreciated the importance of transparency or leveraged technology for more prompt surveillance methods. The call towards such higher order considerations for more timely responses resonates with the need for further reflections for timelier responses.

Additional reflections and research may also draw from the work of Bavel $e t a l,{ }^{18}$ which highlighted a variety of social and behavioural mechanisms that could be useful for responding to COVID-19. Among the strategies highlighted, the risk communication, public persuasion and misinformation denouncement are particularly relevant in times of crisis as they can be quickly implemented. Exploring how health systems have incorporated relevant lessons into their executive branch of government may help inform policymakers what lessons they ought to incorporate into their future health systems coming out of COVID-19. One particularly meaningful avenue is to clarify whether timelier response translates to improvement in lowering deaths or economic costs. As COVID-19 is yet incomplete, future studies might follow-up on this front once COVID-19 resolves.

\section{Limitations}

The lack of change in descriptive statistics for H1N1 inclusion versus exclusion is noteworthy because one would expect that the exclusion of H1N1 would have led to major changes. For example, estimates suggest that the USA might have had 60 million cases. ${ }^{19}$ The removal of H1N1 might have led to little changes in this case due to the data used, which draws from WHO's report of the number of probable $\mathrm{H} 1 \mathrm{~N} 1$ cases. ${ }^{20}$ This data set reported a much smaller number of cases. The USA, for instance, documented only 226 cases in this data set. The advantage of this data set is that it presumably allows for more standardised case definition and comparability across health systems during the epidemic. It is also based on reports by each health system to the WHO. Theoretically then, this is also the figure that would have guided the organisational response at a health system level during the epidemic, which is arguably when most organisational learning would occur. However, this report of H1N1 figure might not represent the actual number of cases and deaths in each health system. It is certainly less accurate than retrospective estimation when more complete information about the disease surfaced. Also, it is difficult to confirm whether this was the data that might have affected the executive branch's ultimate organisational learning activities.

The cross-sectional design limits the interpretation to association, not causation. Further, the lack of health systems previously exposed to major epidemics precludes generalisation across all systems. Health systems with previous epidemics may have developed more timely reporting procedures of policies to $\mathrm{WHO}$, in which case timelier policy responses may actually be merely be an artefact of timelier reporting. The data are limited in that it cannot tease apart such nuances.

Furthermore, the study's interpretation of organisational memory suggests that it is individuals who retain such memory. A tighter study would have variables on individuals' beliefs, knowledge and adaptations for epidemic. The current data set precluded such granular examinations.

Twitter Sian Hsiang-Te Tsuei @SianTsuei

Acknowledgements I would like to thank the following individual for dynamic discussions that helped propel this project: Professor Winnie Chi-Man Yip, Dr Annie Haakenstad, Dr Der-Hwa Tsuei, Ms Kuei-Chun Wu and Dr Amy Tsai. I would also like to thank the two reviewers for their insightful and helpful comments, which significantly strengthened the quality of the work.

Contributors SH-TT contributed to the planning, conduct and reporting of the article. Dr Winnie Yip and Dr Haakenstad provided critical feedback for the development of the project.

Funding This study was funded by Kardvard University (Rose Service Learning Fellowship).

Competing interests SH-TT reports grants from Harvard University-Rose Service Learning Fellowship, outside the submitted work.

Patient and public involvement Patients and/or the public were not involved in the design, or conduct, or reporting or dissemination plans of this research.

Patient consent for publication Not required.

Provenance and peer review Not commissioned; externally peer reviewed.

Data availability statement All data relevant to the study are included in the article or uploaded as supplementary information. All data relevant to the study are uploaded as supplementary files.

Open access This is an open access article distributed in accordance with the Creative Commons Attribution Non Commercial (CC BY-NC 4.0) license, which permits others to distribute, remix, adapt, build upon this work non-commercially, and license their derivative works on different terms, provided the original work is properly cited, appropriate credit is given, any changes made indicated, and the use is non-commercial. See: http://creativecommons.org/licenses/by-nc/4.0/.

\section{REFERENCES}

1 Kluberg SA, Mekaru SR, Mclver DJ, et al. Global capacity for emerging infectious disease detection, 1996-2014. Emerg Infect Dis 2016;22:E1-6.

2 Kandel N, Chungong S, Omaar A, et al. Health security capacities in the context of COVID-19 outbreak: an analysis of international health regulations annual report data from 182 countries. Lancet 2020;395:1047-53.

3 Williams HA, Dunville RL, Gerber SI, et al. CDC's early response to a novel viral disease, middle East respiratory syndrome coronavirus 
(MERS-CoV), September 2012-May 2014. Public Health Rep 2015;130:307-17.

4 Hanvoravongchai P, Adisasmito W, Chau PN, et al. Pandemic influenza preparedness and health systems challenges in Asia: results from rapid analyses in 6 Asian countries. BMC Public Health 2010;10:322.

5 World Health Organization. Health systems: improving performance, 2000. Available: https://www.who.int/whr/2000/en/ [Accessed 3 May 2020].

6 Lega F, Prenestini A, Spurgeon P. Is management essential to improving the performance and sustainability of health care systems and organizations? A systematic review and a roadmap for future studies. Value Health 2013;16:S46-51.

7 Graham-Harrison E. Experience of Sars a key factor in countries' response to coronavirus. The Observer, 2020. Available: https:// www.theguardian.com/world/2020/mar/15/experience-of-sars-keyfactor-in-response-to-coronavirus [Accessed 12 May 2020].

8 Fox J. What prepares a country for a pandemic? An epidemic helps. Bloomberg.com, 2020. Available: https://www.bloomberg.com/ opinion/articles/2020-03-18/covid-19-response-better-in-countrieswith-sars-mers-coronavirus [Accessed 12 May 2020].

9 Walsh JP, Ungson GR. Organizational memory. Acad Manage Rev 1991;16:57-91.

10 Hardt H. NATO's Lessons in Crisis: Institutional Memory in International Organizations. Oxford University Press, 2018.

11 Daselaar SM, Rice HJ, Greenberg DL, et al. The spatiotemporal dynamics of autobiographical memory: neural correlates of recall, emotional intensity, and reliving. Cereb Cortex 2008;18:217-29.

12 Talarico JM, LaBar KS, Rubin DC. Emotional intensity predicts autobiographical memory experience. Mem Cognit 2004;32:1118-32.

13 Labar KS. Beyond fear emotional memory mechanisms in the human brain. Curr Dir Psychol Sci 2007;16:173-7.

14 Wong JY, Kelly H, Ip DKM, et al. Case fatality risk of influenza A (H1N1pdm09): a systematic review. Epidemiology 2013;24:830-41.

15 Roberts M, Hsiao W, Berman P, et al. Getting health reform right: a guide to improving performance and equity. 1st edn. Oxford, New York: Oxford University Press, 2008.

16 Lee T-L. Legal preparedness as part of COVID-19 response: the first 100 days in Taiwan. BMJ Glob Health 2020;5:e002608.

17 Peeri NC, Shrestha N, Rahman MS, et al. The SARS, MERS and novel coronavirus (COVID-19) epidemics, the newest and biggest global health threats: what lessons have we learned? Int J Epidemiol 2020;49:717-26.

18 Bavel JJV, Baicker K, Boggio PS, et al. Using social and behavioural science to support COVID-19 pandemic response. Nat Hum Behav 2020;4:460-71.
19 Shrestha SS, Swerdlow DL, Borse RH, et al. Estimating the burden of 2009 pandemic influenza A (H1N1) in the United States (April 2009-April 2010). Clin Infect Dis 2011;52(Suppl 1):S75-82.

20 WHO. Maps of the spread of influenza A(H1N1). Available: https:// www.who.int/csr/disease/swineflu/h1n1_maps_may/en/ [Accessed 28 May 2020].

21 WHO. Disease outbreaks by year, 2020. Available: http://www.who. $\mathrm{int} / \mathrm{csr} / \mathrm{don} /$ archive/year/en/ [Accessed 28 May 2020].

22 Department of Health. Seychelles, 2020. Available: https://www. facebook.com/pg/mohseychellesofficial/posts/?ref=page_internal [Accessed 28 May 2020].

23 IHME. Geopositioned middle East respiratory syndrome coronavirus occurrences database 1983-2017, 2018. Available: http://ghdx. healthdata.org/record/ihme-data/geopositioned-mers-covoccurrences-database-1983-2017

24 WHO. Summary table of SARS cases by country, 1 November 2002 - 7 August 2003, 2003. Available: https://www.who.int/csr/sars/ country/2003 08 15/en/ [Accessed 28 May 2020].

25 Giahuye JH, Akini B. WHO declares Liberia free of active Ebola virus transmission. Thomson Reuters Foundation news, 2016. Available: https://news.trust.org/item/20160609104923-cft2c/ [Accessed 28 May 2020].

26 Centers for Disease Control and Prevention. 2014-2016 Ebola outbreak in West Africa, 2020. Available: https://www.cdc.gov/vhf/ ebola/history/2014-2016-outbreak/index.html [Accessed 28 May 2020].

27 Roser M, Ritchie H, Ortiz-Ospina E, et al. Coronavirus pandemic (COVID-19). Our World in Data. Available: https://ourworldindata.org/ coronavirus [Accessed 28 May 2020].

28 WHO. Tracking public health and social measures: a global dataset, 2020. Available: https://www.who.int/emergencies/diseases/novelcoronavirus-2019/phsm [Accessed 28 May 2020].

29 Transparency International. Corruption perceptions index, 2020. Available: https://www.transparency.org/en/cpi/2019/press-anddownloads [Accessed 7 Jun 2020].

30 Country Economy. Taiwan GDP - Gross Domestic Product 2018, 2018. Available: https://countryeconomy.com/gdp/taiwan [Accessed 7 Jun 2020].

31 World Bank. GDP per capita (current US\$), 2020. Available: https:// data.worldbank.org/indicator/NY.GDP.PCAP.CD [Accessed 7 Jun 2020].

32 World Bank. Current health expenditure (\% of GDP), 2020. Available: https://data.worldbank.org/indicator/SH.XPD.CHEX.GD.ZS [Accessed 7 Jun 2020].

33 Worldodemeter. Taiwan population, 2020. Available: https://www. worldometers.info/world-population/taiwan-population/ [Accessed 8 Jun 2020].

34 World Bank. Population, total, 2020. Available: https://data. worldbank.org/indicator/SP.POP.TOTL [Accessed 7 Jun 2020]. 